\title{
Psychometric properties of the Shirom-Melamed Burnout Measure (SMBM) among adolescents: results from three cross-sectional studies
}

\author{
Markus Gerber* $\mathbb{D}^{*}$, Flora Colledge, Manuel Mücke, René Schilling, Serge Brand and Sebastian Ludyga
}

\begin{abstract}
Background: Burnout has long been understood as work-related physical, emotional, and cognitive exhaustion. However, burnout symptoms can also be found among younger people, including school-aged adolescents. While the Shirom-Melamed Burnout Measure (SMBM) is a widely applied instrument, its psychometric properties have not yet been investigated in adolescent populations. We therefore examined the psychometric properties of the SMBM in three independent samples of adolescents.

Methods: In total, 249 high school students, 144 vocational students, and 257 adolescent elite athletes completed the SMBM, along with questionnaires related to perceived stress, depressive symptoms, and life satisfaction.

Descriptive statistics, gender differences, and internal consistency, convergent/discriminant validity, and factorial validity (including measurement invariance across genders) were examined in each sample.

Results: The SMBM had adequate internal consistency. Confirmatory factor analyses showed that both a first- and second-order model achieve good model fit. Moreover, evidence for sufficient convergent and discriminant validity was found. Finally, in two of the three samples, female adolescents reported higher SMBM scores.

Conclusions: The SMBM has been widely used in international burnout research. However, this is the first study providing empirical evidence that the SMBM has acceptable psychometric properties and satisfactory convergent/ discriminant and factorial validity among young people. The SMBM is a concise and economic tool to assess selfrated symptoms of burnout, and presents a valuable alternative to existing school burnout inventories. In particular, the SMBM can facilitate the investigation of the transition of young people from school to working life.
\end{abstract}

Keywords: Burnout, Mental wellbeing, Measurement invariance, Stress, Validity

\section{Background}

Burnout is a complex phenomenon with more than 40 years of empirical research [1]. Burnout was initially defined as a work-related syndrome that gradually develops when people are exposed to chronic emotional and interpersonal stress at work [2]. While researchers generally agree that burnout is a multidimensional construct [3-5], different conceptualizations of burnout have been proposed by different groups of researchers [6]. Drawing on Hobfoll's Conservation of Resources

\footnotetext{
* Correspondence: markus.gerber@unibas.ch

Department of Sport, Exercise and Health, University of Basel, St. Jakobsturm, Birsstrasse 320B, 4052 Basel, Switzerland
}

(COR) theory, Melamed et al. [7] argued that the central characteristics of the burnout construct are emotional exhaustion, physical fatigue, and cognitive weariness.

Based on Shirom, Melamed et al.'s [8, 9] definition of burnout, researchers have shown that burnout has an impact on both physical and mental health outcomes: For instance, burnout was found to be a risk factor for increased total cholesterol, low-density lipoprotein cholesterol and triglyceride levels [7, 10-12], increased fasting glucose and risk of developing type 2 diabetes $[13,14]$, increased inflammatory markers $[12,15]$, increased leukocyte adhesiveness [16], increased diurnal cortisol levels [17], elevated cortisol response after

(c) The Author(s). 2018 Open Access This article is distributed under the terms of the Creative Commons Attribution 4.0 International License (http://creativecommons.org/licenses/by/4.0/), which permits unrestricted use, distribution, and 
awakening [18], increased risk of musculoskeletal pain [19], and a higher likelihood of fertility problems [20]. As regards psychological dimensions, data revealed that burnout symptoms constitute a risk for poor life satisfaction and quality of sleep [17, 21]. Similarly, significant relationships were observed between burnout and depression, with varying degrees of overlap [15, 22-24].

While the above findings underscore that burnout symptoms are a cause of concern from a public health perspective [25], most of the existing evidence is based on working adults and therefore cannot be generalized to young people. Nevertheless, several researchers have claimed that the concept of burnout is pertinent beyond the occupational context and also concerns student populations [26, 27]. More specifically, Salmela et al. [27] have argued that school-aged adolescents and university students - by attending classes, completing assignments, taking examinations, and acquiring a degree - also execute work. As a consequence, researchers have developed instruments specifically designed for young people. For instance, based on the Maslach Burnout Inventory (MBI) [4], Schaufeli et al. [26] have created a 15-item instrument for university students, which consists of three dimensions: exhaustion, cynicism, and professional efficacy. This instrument was well received by the scientific community, and has stimulated a large number of studies to examine the associations with academic performance and various health-related outcomes [28-34]. Some years later, Salmela-Aro and Näätänen [35] developed an instrument to assess burnout among school-aged children, the School Burnout Inventory (SBI). On the basis of the Bergen Burnout Indicator 15 (BBI-15) [36, 37], burnout was conceptualized as a three-dimensional construct consisting of the following subdomains: exhaustion at school (four items), cynicism toward the meaning of school (three items), and sense of inadequacy at school (three items). Evidence supported the validity and reliability of the SBI [27], and based on this tool, researchers were able to gain further insights into risk factors [38-44], time courses [42, 45], and health consequences associated with school burnout [46-48] among adolescents.

In summary, it can be concluded that research on burnout among school-aged adolescents has increased significantly in the last ten years. However, it is also obvious that the existing research has been dominated by the SBI. While this instrument has sound psychometric properties [27], the school-specific conceptualization of the construct makes it difficult to compare the SBI scores with those of adult populations, and complicates research focusing on the transition from school to working life. As highlighted by Walburg [49] in her review on adolescent school burnout, only a few alternative instruments have been applied in this age group. Nevertheless, some researchers have used the Shirom Melamed Burnout Measures (SMBM) [7, 16] as an alternative to assess burnout symptoms in adolescent students. In these studies, higher scores on the SMBM were associated with more depressive symptoms, more sleep problems, lower life satisfaction, and poorer quality of sleep [50]. Moreover, adolescents who accomplished recommended levels of physical activity reported lower SMBM scores [51], and the relationship between adolescents' stress and burnout scores was moderated by their levels of mental toughness [52].

Although the SMBM seems to have satisfactory internal consistency among adolescents [50-52], the validity and reliability of the SMBM have not yet been examined systematically in young people. Compared to the SBI, the advantage of the SMBM is that the measure is rooted in Hobfoll's Conservation of Resources theory [53], and thus has a clear theoretical background. Moreover, the items of the SMBM are context unspecific, and thus allow a comparison between varied samples of adolescents. Finally, the SMBM allows a comparison between burnout symptoms of adolescents and adults, is well suited to examining transitions from adolescence to adulthood, and provides a cut-off pointing towards clinically relevant levels of burnout [54]. Therefore, the purpose of the present study was to validate the SMBM in three samples of adolescents attending different types of public schools in Switzerland. We claim that these analyses are warranted because the SMBM has been widely used in (adult) burnout research during the last 25 years [24], and because it is time to find out whether this instrument is also suitable for younger people.

In the present article, six hypotheses will be tested: First, we expect that the SMBM will produce adequate internal consistency across all student samples. Thus, we expect inter-item correlations of $\geq .20$, Cronbach's alpha coefficients of $\geq .70$, and item-total correlations of $\geq .30$ $[16,55,56]$. Second, regarding factorial validity, we expect that adequate model fit will be found for a three-factor model $[55,56]$. We also expect that adequate model fit will occur for a first- and second-order model [55]. More specifically, with reference to the standards defined by Comrey et al. [57] and based on previous findings $[55,56]$, we expect very good factor loadings $(\geq .63)$ across all items on the corresponding factors. Third, we expected to find adequate convergent validity. That is, we hypothesize that the SMBM subscales and the SMBM overall index will be moderately to strongly (and positively) correlated with perceived stress [58-60] and the School Burnout Inventory (SBI) [51], ${ }^{1}$ while we expect a moderate (negative) relationship between the SMBM and adolescents' life satisfaction [61]. Fourth, as an indication of discriminant validity, we assume that only moderate (positive) correlations will 
exist between the SMBM and self-reported depressive symptoms [24, 61]. Fifth, we expect that girls will score higher on the SMBM than boys [59, 61, 62]. Sixth, we expect the measurement model to be invariant across samples.

\section{Methods}

\section{Sample 1: High school students}

\section{Participants and procedures}

Sample 1 consisted of 249 students attending three high schools in the North-Western, German-speaking part of Switzerland (age: $M=16.09$ years, $S D=1.00,89$ boys, 160 girls). From each school, five classes were randomly selected. Paper-and-pencil questionnaires were completed in a group setting during official class time (during the second month of the school year between September-October). Students were informed that participation was voluntary and that their responses would be treated confidentially. Inclusion criteria were: (a) informed written consent, (b) aged between 14 and 20 years, and (c) attending a selected class of one of the three high schools. None of the eligible participants had to be excluded. All participants provided written informed consent ${ }^{2}$. The study was approved by the local ethics committee.

\section{Burnout}

Burnout symptoms were assessed with the 14-item SMBM [16, 17]. The original SMBM consists of the three subscales labelled physical fatigue (six items: e.g., "I feel physically drained." or "I feel fed-up."), cognitive weariness (five items: e.g., "I feel I am not thinking clearly." or "I have difficulty concentrating."), and emotional exhaustion (three items: e.g., "I feel I am unable to be sensitive to the needs of coworkers and customers." or "I feel I am not capable to being sympathetic to coworkers and customers."). The wording of the three items assessing emotional exhaustion was slightly changed to make the items more suitable for adolescents. Thus, instead of referring to coworkers and customers, we used a more open formulation, and referred to people in general (see Additional file 1 for items in German language).

\section{Perceived stress}

Perceived stress during the past month was assessed with the widely used 10-item Perceived Stress Scale (PSS) [63]. Participants were asked how often they find their lives to be overwhelming, uncontrollable, and unpredictable (e.g., "In the last month, how often have you felt that you were effectively coping with important changes that were occurring in your life?", "In the last month, how often have you been upset because of something that happened unexpectedly?"). Answers were given on a 5-point Likert scale, ranging from 1 (never) to 5 (very often). Four items were reverse-poled and had to be recoded before calculating the sum score. Higher scores reflected higher subjectively perceived stress levels. Evidence for the reliability and validity of this instrument has been provided previously $[64,65]$. In the present sample, the Cronbach's alpha was satisfactory $(\alpha=.85)$.

\section{Depressive symptoms}

To assess depressive symptoms, all students filled in a German version of the Center for Epidemiologic Studies Depression Scale (CES-D), which is a self-report measure intended for research in general non-psychiatric populations. The instrument comprises 15 items assessing cognitive, emotional, motivational, behavioral, and somatic aspects associated with depression [66]. Previous studies with adolescents have demonstrated the validity and adequate internal consistency of the CES-D [67]. Items used a 4-point scale with response options of 0 (<1 d/wk), 1 (1-2 d/wk), 2 (3-4 d/wk), and $3(5-7 \mathrm{~d} / \mathrm{wk})$. The reverse-score was calculated for positively worded items, before building the sum score. Scores $>17$ are generally considered as high [66]. The Cronbach's alpha in the present sample was .86.

\section{Life satisfaction}

An overall judgement of participants' satisfaction with life was obtained through the 5-item Satisfaction with Life Scale (SWLS) [68]. Answers were given on a Likert-scale from 1 (strongly disagree) to 7 (strongly agree). A sample item is: "In most ways my life is close to my ideal." Validity and adequate reliability of this instrument have been reported previously [69, 70]. A sum score was built with higher scores reflecting higher satisfaction with life (the Cronbach's alpha in the present sample was .84).

\section{Statistical analyses}

Correlational analyses were used to examine homogeneity and item-total correlations. Cronbach's alpha coefficients were obtained to test internal consistency. We used confirmatory factor analysis (CFA) to examine factorial validity. We assumed that the 14 items would load on three different factors (six items on physical exhaustion, five items on cognitive weariness, three items on emotional exhaustion). Thus, the 3-factor CFA model was based on 14 observed measures and three latent constructs. Parameter estimation was conducted using maximum likelihood (ML), and multiple goodness-of-fit indexes were considered to examine how well the theoretical model fitted the empirical data [71]. Byrne [72] recommended that normed fit index (NFI) should 
be $\geq .95$, comparative fit index $(\mathrm{CFI}) \geq .95$, Tucker Lewis Index $(\mathrm{TLI}) \geq .95$, and root mean square error of approximation $($ RMSEA) $\leq .05$. According to Comrey and Lee [57], standardized factor loadings of $\geq .71$ should be interpreted as excellent, $\geq .63$ as very good, $\geq .55$ as good, $\geq .45$ as fair, and $>.32$ as poor. Correlations were employed to test convergent and discriminant validity, while we used univariate analyses of variance (ANOVA) to examine gender differences. To further test discriminant validity, we performed $\chi^{2}$ test to examine the overlap between students classified as having clinically relevant burnout symptoms and high depressive symptoms. CFA were performed with $\mathrm{AMOS}^{\circ} 24$ (IBM Corporation, Armonk NY, USA), all other analyses with SPSS $^{\circ} 24$ (IBM Corporation, Armonk NY, USA).

\section{Results}

As shown in Table 1, the SMBM overall score was 3.24 $(S D=0.99)$. Moreover, $12 \%(n=30)$ of the participants were categorized as having clinically relevant levels of burnout ( $\geq 4.40)$. Compared to males, females had higher scores in physical exhaustion (females: $M=$ 3.89, $S D=1.24$, males: $M=3.19, S D=1.03)$, cognitive weariness (females: $M=3.38, S D=1.13$, males: $M=$ 2.93, $S D=1.07$ ), and overall burnout (females: $M=$ 3.44, $S D=0.99$, males: $M=2.96, S D=0.84)$. Compared to males $(n=2,2.2 \%)$, females $(n=28,17.5 \%)$ were also significantly overrepresented in the group with clinically relevant burnout symptoms, $\chi^{2}(1, N=247)=$ $12.45, p<.001$.

For each of the three SMBM subscales, the inter-item correlations exceeded the critical value of .20, and all item-total correlations were above the threshold of .40 . The Cronbach's alpha was .90 for physical exhaustion, .91 for cognitive weariness, .88 for emotional exhaustion, and .92 for the SMBM overall index.

The three-factor model fitted well with the empirical data in the CFA (Table 2). This conclusion applies for both the first- and second-order model. All factor loadings were very good to excellent $(\geq .63)$. Figure 1 displays the measurement coefficients of the hypothesized three-factor models. In the first-order model, moderate-to-strong correlations were observed between the three SMBM dimensions $(r=.37$ to $.72, p<.001)$.

With regard to convergent and discriminant validity, significant positive correlations were found between the SMBM and the PSS. While correlations with perceived stress were moderate to high for physical exhaustion, cognitive weariness, and overall burnout, only a weak (but significant) correlation occurred for emotional exhaustion. Significant negative correlations (of moderate magnitude) were found between satisfaction with life and three of four burnout indices (physical exhaustion, cognitive weariness, overall burnout). While the correlation of the emotional exhaustion subscale and life satisfaction pointed in the expected direction, the relationship was not significant. Moreover, moderate to strong correlations were found between the SMBM indices and depressive symptoms. Thus, the SMBM indices and the CES-D shared between 9 and $41 \%$ of variance. Finally, among those 28 students with high depressive symptoms (CES-D scores $>17), 53.6 \%(n=15)$ also had clinically relevant burnout, whereas $46.4 \%$ did not $(n=13)$.

\section{Sample 2: Vocational students Methods \\ Participants and procedures}

The sample consisted of 144 first-year students (age: $M=16.22$ years, $S D=1.13$, 97 males, 47 females) who were recruited from a vocational school in the Eastern part of Switzerland. Professions studied included polytechnicians, retail assistants, industrial clerks, structural draftsmen, and hair dressers. Questionnaires were completed within students' classrooms under supervision of a trained research assistant (during the second month of the school year in September-October). Prior to data assessment, detailed information was given to the students about the purpose of the study and the voluntary nature of their participation. Students were assured confidentiality of their responses and informed written consent was sought from the participants. ${ }^{2}$ Inclusion criteria were: (a) informed written consent, (b) aged between 14 and 20 years, and (c) attending the selected vocational schools. None of the eligible participants were excluded. Ethical clearance was granted by the local ethical committee.

\section{Burnout}

To assess burnout symptoms, the participants filled in the 14-item Shirom-Melamed Burnout Measure (SMBM) [16], which has been described in detail in the introduction section (and above for sample 1). Additionally, vocational students completed the School Burnout Inventory (SBI) [27], which assesses exhaustion at school (4 items: e.g., "I feel overwhelmed by my schoolwork."), cynicism toward the meaning of school (3 items: e.g., "I feel a loss of interest in my schoolwork."), and feeling a sense of inadequacy at school (2 items: e.g., "I used to have higher expectations for my schoolwork than I have now."). Answers on the SBI were given on a 6-point Likert scale ranging from 1 (completely disagree) to 6 (completely agree). Mean scores were built to obtain SBI subscale scores and an overall school burnout score, with higher values being indicative of higher school burnout levels. Evidence for the validity of this instrument has been reported previously [27]. In the present sample, the Cronbach's alphas were .82 for the overall SBI index, .76 for exhaustion at school, 
Table 1 Descriptive statistics for the three samples, test of gender differences, and bivariate correlations between SMBM subscales and the overall SMBM index

\begin{tabular}{|c|c|c|c|c|c|c|c|}
\hline & M & SD & Range & Skew & Kurt & ANOVA & \\
\hline \multicolumn{8}{|c|}{ Sample 1: High school students $(N=249)$} \\
\hline Descriptive statistics & & & & & & $\mathrm{F}$ & $\eta^{2}$ \\
\hline Physical exhaustion & 3.64 & 1.21 & $1.00-6.67$ & 0.15 & -0.51 & $20.35^{* * *}$ & .076 \\
\hline Cognitive weariness & 3.22 & 1.13 & $1.00-7.00$ & 0.12 & -0.15 & $9.58^{* *}$ & .037 \\
\hline Emotional exhaustion & 2.34 & 1.57 & $1.00-6.67$ & 1.04 & 1.24 & 0.34 & .001 \\
\hline Overall SMBM index & 3.24 & 0.99 & $1.00-5.93$ & 0.04 & -0.34 & $14.68^{* * *}$ & .056 \\
\hline Bivariate correlations & 1. & 2. & 3. & 4. & & & \\
\hline 1. Physical exhaustion & - & & & & & & \\
\hline 2. Cognitive weariness & $68^{* * *}$ & - & & & & & \\
\hline 3. Emotional exhaustion & $.35^{* * *}$ & $.39 * * *$ & - & & & & \\
\hline 4. Overall SMBM index & $.91^{* * *}$ & $.85^{* * *}$ & $.42^{* * *}$ & - & & & \\
\hline \multicolumn{8}{|c|}{ Sample 2: Vocational students $(N=144)$} \\
\hline Descriptive statistics & & & & & & $\mathrm{F}$ & $\eta^{2}$ \\
\hline Physical exhaustion & 3.15 & 1.09 & $1.17-5.83$ & 0.29 & -0.56 & 1.43 & .010 \\
\hline Cognitive weariness & 2.98 & 1.01 & $1.00-5.60$ & 0.20 & -0.73 & 0.04 & .000 \\
\hline Emotional exhaustion & 2.40 & 1.13 & $1.00-7.00$ & 0.95 & 1.16 & 3.61 & .025 \\
\hline Overall SMBM index & 2.93 & 0.91 & $1.14-5.07$ & 0.22 & -0.78 & 1.05 & .007 \\
\hline Bivariate correlations & 1. & 2. & 3. & 4. & & & \\
\hline 1. Physical exhaustion & - & & & & & & \\
\hline 2. Cognitive weariness & $.68^{* * *}$ & - & & & & & \\
\hline 3. Emotional exhaustion & $.48^{* * *}$ & $.52^{* * *}$ & - & & & & \\
\hline 4. Overall SMBM index & $.91^{* * *}$ & $.88^{* * *}$ & $.72^{* * *}$ & - & & & \\
\hline \multicolumn{8}{|c|}{ Sample 3: Young elite athletes $(N=257)$} \\
\hline Descriptive statistics & & & & & & $\mathrm{F}$ & $\eta^{2}$ \\
\hline Physical exhaustion & 3.55 & 1.13 & $1.33-6.67$ & 0.30 & -0.40 & $4.00^{*}$ & .015 \\
\hline Cognitive weariness & 3.35 & 1.08 & $1.00-7.00$ & 0.43 & 0.34 & $5.18^{*}$ & .020 \\
\hline Emotional exhaustion & 2.80 & 1.16 & $1.00-6.67$ & 0.53 & 0.01 & 0.19 & .001 \\
\hline Overall SMBM index & 3.32 & 0.96 & $1.29-6.79$ & 0.46 & 0.33 & 2.91 & .011 \\
\hline Bivariate correlations & 1. & 2. & 3. & 4. & & & \\
\hline 1. Physical exhaustion & - & & & & & & \\
\hline 2. Cognitive weariness & $.65^{* * *}$ & - & & & & & \\
\hline 3. Emotional exhaustion & $.49^{* * *}$ & $.47^{* * *}$ & - & & & & \\
\hline 4. Overall SMBM index & $.89^{* * *}$ & $.86^{* * *}$ & $.71^{* * *}$ & - & & & \\
\hline
\end{tabular}

Note. Skew $=$ Skewness, Kurt $=$ Kurtosis

${ }^{*} p<.05 .{ }^{* *} p<.01 .{ }^{* * *} p<.001$

.80 for cynicism toward the meaning of school, and .55 for sense of inadequacy at school.

\section{Perceived stress}

A 30-item version of the Adolescent Stress Questionnaire (ASQ) [73] was used to measure perceived general stress in this sample. Items pertain to ten domains of potential stressful experiences, including arguments at home, teachers expecting too much from them, pressure to fit in with peers or concerns about their future. For each stressor, answers were given on a 5-point Likert scale from 1 (not at all stressful or irrelevant) to 5 (very stressful). Satisfactory psychometric properties for this instrument have been reported previously [64, 74]. In the present sample, the Cronbach's alpha was .90 .

\section{Depressive symptoms}

Depressive symptoms were assessed with the 15-item CES-D [66], as previously described for sample 1 (Cronbach's alpha in this sample was .81). 
Table 2 Goodness-of-fit indices

\begin{tabular}{|c|c|c|c|c|c|c|c|c|}
\hline & \multicolumn{4}{|c|}{ First-order model } & \multicolumn{4}{|c|}{ Second-order model } \\
\hline & $\overline{\mathrm{CFI}}$ & TLI & $\mathrm{NFI}$ & RMSEA & $\overline{\mathrm{CFI}}$ & TLI & $\mathrm{NFI}$ & RMSEA \\
\hline \multicolumn{9}{|c|}{ Sample 1: High school students } \\
\hline Default model & .99 & .99 & .97 & $.03(.00, .05)$ & .99 & .99 & .97 & $.03(.00, .05)$ \\
\hline \multicolumn{9}{|c|}{ Sample 2: Vocational students } \\
\hline Default model & .96 & .97 & .93 & $.06(.04, .08)$ & .96 & .97 & .93 & $.04(.06, .08)$ \\
\hline \multicolumn{9}{|c|}{ Sample 3: Young elite athletes } \\
\hline Default model & .95 & .96 & .93 & $.06(.05, .08)$ & .95 & .96 & .93 & $.06(.05, .08)$ \\
\hline
\end{tabular}

CFI Comparative fit index, TLI Tucker Lewis index, NFI Normed fit index, RMSEA Root mean square error of approximation

\section{Life satisfaction}

Satisfaction with life was assessed with the 5-item SWLS [68], as previously described for sample 1 . In this sample, the Cronbach's alpha was .82 .

\section{Statistical analyses}

The same statistical procedures were used as with sample 1.

\section{Results}

The SMBM overall mean score was $2.93(S D=0.91)$ (Table 1). In total, $6.9 \%(n=10)$ of the participants reported clinically relevant burnout levels (SMBM scores $\geq 4.40$ ). Similarly, $6.9 \%$ of the participants reported high levels of depressive symptoms (CES-D scores >17). No significant gender differences existed among vocational students with regard to the SMBM overall index and subscale scores (Table 1). Boys $(n=7$, $72 . \%)$ and girls $(n=3,6.4 \%)$ were equally represented in the group with clinically relevant burnout symptoms, $\chi^{2}(1, N=144)=0.03, p>.05$.

For each of the three SMBM subscales, all inter-item correlations exceeded the critical value of .20. Similarly, all item-total correlations were satisfactory, with correlations exceeding the threshold of .40. The Cronbach's alpha was .90 for physical exhaustion, .90 for cognitive weariness, .82 for emotional exhaustion, and .93 for the SMBM overall index.

With regard to factorial validity, the model fit of the three-factor model was adequate, with all goodness-of-fit indices being close or exceeding the targeted cut-offs, both for the first-order and second-order model (Table 2). Most of the factor loadings were very good or higher $(\geq .63)$. Figure 1 provides the measurement coefficients of the hypothesized three-factor models. In the first-order model, relatively strong correlations were observed between the three SMBM dimensions $(r=.57$ to $.78, p<.001)$.

With regard to convergent and discriminant validity (Table 3), the SMBM overall index was positively associated with participants' perceived stress levels $(r=.54$, $p<.001)$. Moderate negative correlations were observed between the SMBM indices and satisfaction with life $(r=-.33$ to $-.41, p<.001)$, while moderate-to-strong correlations existed between the SMBM indices and the SBI overall scale $(r=.41$ to $.69, p<.001)$. Additional analyses showed that participants with clinically relevant burnout symptoms (SMBM score $\geq 4.40$ ) reported significantly higher overall school burnout levels $(M=3.62, S D=$ 0.54; $\left.F[1,247]=14.82 p<.001, \eta^{2}=.056\right)$ than peers below this threshold $(M=2.50, S D=0.74)$. Moderate positive correlations were also found between the SMBM indices and the CES-D $(r=.29$ to $.47, p<.001)$. Among those students with high levels of depressive symptoms (CES-D scores $>17), 80 \%(n=8)$ did not have clinically relevant burnout levels $(\mathrm{SMBM} \geq 4.40)$, whereas $20 \%(n=2)$ did.

\section{Sample 3: Young elite athletes Methods Participants and procedures}

Sample 3 was composed of 257 young elite athletes attending Swiss Olympic Sport Classes in the North-Western, German-speaking part of Switzerland. Students from all Swiss Olympic Sport Classes from four Swiss cantons (Basel-City, Basel-Country, Argovia, Solothurn) were eligible for the study. Further inclusion criteria were: (a) informed written consent, (b) aged between 14 and 20 years. Students were assured confidentiality, and participation was voluntary. All students provided written informed consent before they responded to a written questionnaire, and none of the eligible participants were excluded. $^{2}$ The data assessment took place during the second month of the school year (SeptemberOctober). The study was approved by the local ethics committee. The sample consisted of 163 males and 94 females (age: $M=16.82$ years, $S D=1.44$ ).

\section{Burnout}

Burnout was assessed with the 14-item SMBM, in exactly the same way as with samples 1 and 2 . 


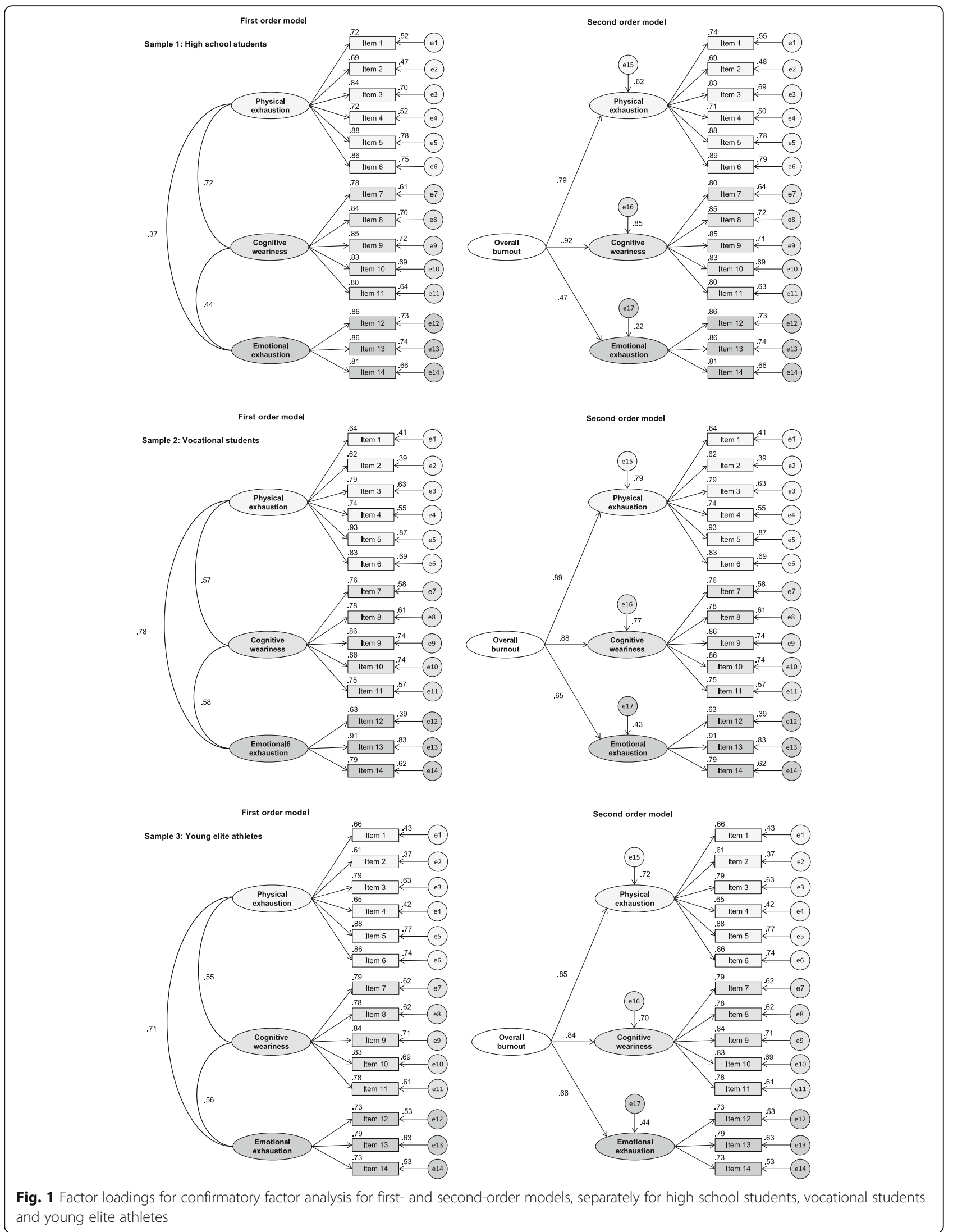


Table 3 Bivariate correlations between burnout symptoms, perceived stress, depressive symptoms and satisfaction with life

\begin{tabular}{|c|c|c|c|c|}
\hline & Physical exhaustion & Cognitive weariness & Emotional exhaustion & Overall SMBM index \\
\hline \multicolumn{5}{|c|}{ Sample 1: High school students $(N=249)$} \\
\hline Perceived stress (PSS) & $.58^{* * *}$ & $.55^{* * *}$ & $24^{* * *}$ & $.37^{* * *}$ \\
\hline Depressive symptoms (CES-D) & $.64^{* * *}$ & $.60^{* * *}$ & $.30^{* * *}$ & $.51^{* * *}$ \\
\hline Satisfaction with life (SWLS) & $-.39^{* * *}$ & $-.39 * * *$ & -.10 & $-.25^{* * *}$ \\
\hline \multicolumn{5}{|c|}{ Sample 2: Vocational students $(N=144)$} \\
\hline Perceived stress (ASQ) & $.35^{* * *}$ & $.50^{* * *}$ & $.42^{* * *}$ & $.54^{* * *}$ \\
\hline Depressive symptoms (CES-D) & $.42^{* * *}$ & $.46^{* * *}$ & $.29^{* * *}$ & $.47^{* * *}$ \\
\hline Satisfaction with life (SWLS) & $-.33^{* * *}$ & $-.34^{* * *}$ & $-.38^{* * *}$ & $-.41^{* * *}$ \\
\hline Overall school burnout (SBI) & $.66^{* * *}$ & $.62^{* * *}$ & $.41^{* * *}$ & $.69^{* * *}$ \\
\hline Exhaustion at school & $.47^{* * *}$ & $.51^{* * *}$ & $29^{* * *}$ & $.52^{* * *}$ \\
\hline Cynicism toward school & $.61^{* * *}$ & $.48^{* * *}$ & $.33^{* * *}$ & $.59^{* * *}$ \\
\hline Sense of inadequacy & $.37^{* * *}$ & $.47^{* * *}$ & $.26^{* * *}$ & $.44^{* * *}$ \\
\hline \multicolumn{5}{|c|}{ Sample 3: Young elite athletes $(N=257)$} \\
\hline Perceived stress (PSS) & $.48^{* * *}$ & $.48^{* * *}$ & $.37^{* * *}$ & $.55^{* * *}$ \\
\hline Depressive symptoms (PHQ9) & $.38^{* * *}$ & $.37^{* * *}$ & $.23^{* * *}$ & $.39^{* * *}$ \\
\hline Satisfaction with life (SWLS) & $-.36^{* * *}$ & $-.34^{* * *}$ & $-.35^{* * *}$ & $-.43^{* * *}$ \\
\hline
\end{tabular}

SMBM Shirom-Melamed Burnout Measure, PSS Perceived Stress Scale, CES-D Center for Epidemiologic Studies Depression Scale, PHQ9 Patient Health Questionnaire 9, SBI School Burnout Inventory. SWLS Satisfaction with Life Scale

${ }^{*} p<.05 .{ }^{* *} p<.01 .{ }^{* * *} p<.001$

\section{Perceived stress}

Perceived stress was assessed with the 10-item PSS [63], as described above for sample 1 (Cronbach's alpha in this sample was .80).

\section{Depressive symptoms}

Depressive symptoms were assessed with the 9-item Patient Health Questionnaire [75]. The PHQ-9 refers to the DSM-IV diagnosis criteria for major depressive disorder. Major depression is diagnosed if at least five of the nine depressive symptom criteria have been present on at least "more than half the days" in the past 2 weeks, and if one of the symptoms is depressed mood or anhedonia. The PHQ-9 can also be used to assess severity of depressive symptoms, with scores of $>14$ reflecting moderately severe depression. The Cronbach's alpha was .85 in the present sample.

\section{Life satisfaction}

Satisfaction with life was assessed with the 5-item SWLS [68], as previously described for samples 1 and 2 . In this sample, the Cronbach's alpha was .80 .

\section{Statistical analyses}

The same statistical procedures were used as with samples 1 and 2.

\section{Results}

As shown in Table 1, the SMBM overall score was 3.32 $(S D=0.96)$ in the total sample (Table 1$)$. Furthermore,
$12.1 \%(n=31)$ of the participants reported clinically relevant burnout symptoms $(\geq 4.4)$, whereas $8.9 \%(n=23)$ reported moderately severe depression (PHQ-9 scores $>14$ ). As in sample 1, females reported significantly higher scores (see Table 1) for physical exhaustion (females: $M=3.73, \mathrm{SD}=3.44$, males: $M=3.44, S D=1.10$ ) and cognitive weariness (females: $M=3.55, \mathrm{SD}=1.13$, males: $M=3.23, S D=1.03)$. However, no significant gender differences were observed for the SMBM overall index and the emotional exhaustion subscale, and boys and girls were equally represented among participants with clinically relevant burnout levels.

For each of the three SMBM subscales, inter-item correlations were above .20, and all item-total correlations exceeded the threshold of .40 (for both males and females). The Cronbach's alpha in the total sample was .88 for physical exhaustion, .90 for cognitive weariness, .80 for emotional exhaustion, and .92 for the SMBM overall index.

Good model fit was observed for the three-factor model in the CFA (Table 2). The model fit was comparable for the first- and second-order model. As shown in Fig. 1, most factor loadings were very good or excellent $(\geq$.63). In the first-order model, relatively strong correlations existed between the three SMBM subscales $(r=.55$ to $.71, p<.001)$.

The significant positive correlations between the SMBM overall index and subscales and the PSS support the convergent validity of the instrument (Table 3 ). Significant negative correlations were observed between 
the four SMBM indices and satisfaction with life, while significant positive correlations of weak to moderate strength ( $r=.23$ to $.39, p<.01$ ) were found between the SMBM indices and depressive symptoms. Finally, among those students with moderately severe depression (PHQ-9 scores > 14), 26.1\% $(n=6)$ also had clinically relevant burnout levels, whereas $73.9 \%$ did not $(n=17)$.

\section{Testing measurement invariance of the SMBM across all samples Methods \\ Participants}

To test measurement invariance across samples, the samples $1-3$ were merged $(n=650)$. The overall sample consisted of 349 males and 301 females (age: $M=$ 16.41 years, $S D=1.26$ ).

\section{Burnout}

Across all samples, burnout symptoms were assessed in exactly the same way with the 14-item SMBM.

\section{Statistical analyses}

To test measurement invariance of the SMBM across all three samples, we carried out simultaneous multiple group comparisons. As reported previously, we assumed a 3-factor CFA model, based on 14 observed measures and three latent constructs. In this default model, all parameters were freely estimated. This model was then compared against a model in which all free factor loadings were set equally across the three samples. In a next step, we then tested this model against a model in which we assumed invariant factor loadings and inter-factor correlations (first-order model) or regression weights between the first- and second-order factors (second-order model). Again, multiple goodness-of-fit indices were considered to examine how well the theoretical model fitted with the empirical data (for more details, see description of statistical analyses for sample 1).

\section{Results}

In the merged sample, the mean score was $M=3.40$ $(S D=1.17)$ for physical exhaustion, $M=3.22(S D=1.09)$ for cognitive weariness, and $M=2.54(S D=1.17)$ for emotional exhaustion.

The three-factor solution of the SMBM was supported (Fig. 2). As shown in Table 4, both the first-order and second-order model showed good fit between the theoretical model and the empirical data. The non-significant $\Delta \mathrm{X}^{2}$-test showed that setting the factor loadings equal across samples did not lead to a worse model fit. Similarly, setting inter-factor correlations (first-order model) or regression weights (second-order model) equally across samples did not negatively impact the model fit $\left(\Delta \mathrm{X}^{2}\right.$-test: $\left.p=n s\right)$.
In the merged sample, the inter-item correlations exceeded the critical value of .20 for each of the three SMBM subscales, and all item-total correlations were above the threshold of .40. The Cronbach's alpha was .90 for physical exhaustion, .91 for cognitive weariness, .88 for emotional exhaustion, and .92 for the SMBM overall index.

\section{Result and Discussion}

The key finding of the present article is that among adolescents the SMBM has excellent psychometric properties and acceptable convergent/discriminant validity and can therefore be used as an alternative screening instrument in adolescent samples. Finally, our data confirm that clinically relevant burnout symptoms may already occur at young age.

In the introduction section, we have proposed six hypotheses, which we will now discuss in detail. First, we expected that the SMBM would have acceptable internal consistency across all samples $[16,55,56]$. This assumption was supported, with all Cronbach's alpha coefficients exceeding the critical value of $\geq .70$. Moreover, without exception, all inter-item correlations within the respective factor were $\geq .20$, and all item-total correlations were $\geq .40$. Based on the standards suggested by West et al. [76], we further found that the skewness $(<2)$ and kurtosis $(<7)$ of all SMBM indices were in the acceptable range.

Second, using CFA, evidence was found for the factorial validity of the SMBM across all our adolescent populations. Thus, our assumption that a three-factorial model would produce adequate fit was confirmed. In accord with prior research [55], almost all factor loadings were very good or excellent in our sample. The first-order model revealed moderate-to-strong correlations between the three latent factors, which is in line with previous research (cp. $[6,56,62])$. Shirom and Melamed [6] argued that energetic resources are individually possessed and expected to be closely interrelated, with deficits in one resource often leading to a deficit in other resource. Therefore, moderate-to-strong correlations between the latent factors were expected. Finally, in support of findings from data of Canadian workers [55], a second-order model produced equally good model fit, which corroborates the idea that the SMBM overall index can be used as a global/general measure of burnout.

Third, our analyses support the convergent validity of the SMBM across all samples. As reported in prior investigations with adult populations [58-60], our data suggest that the SMBM indices correlated at least moderately and positively with measures of self-perceived stress. Finally, across all samples moderate negative correlations were found for most of the SMBM indices and adolescents' satisfaction with life, 


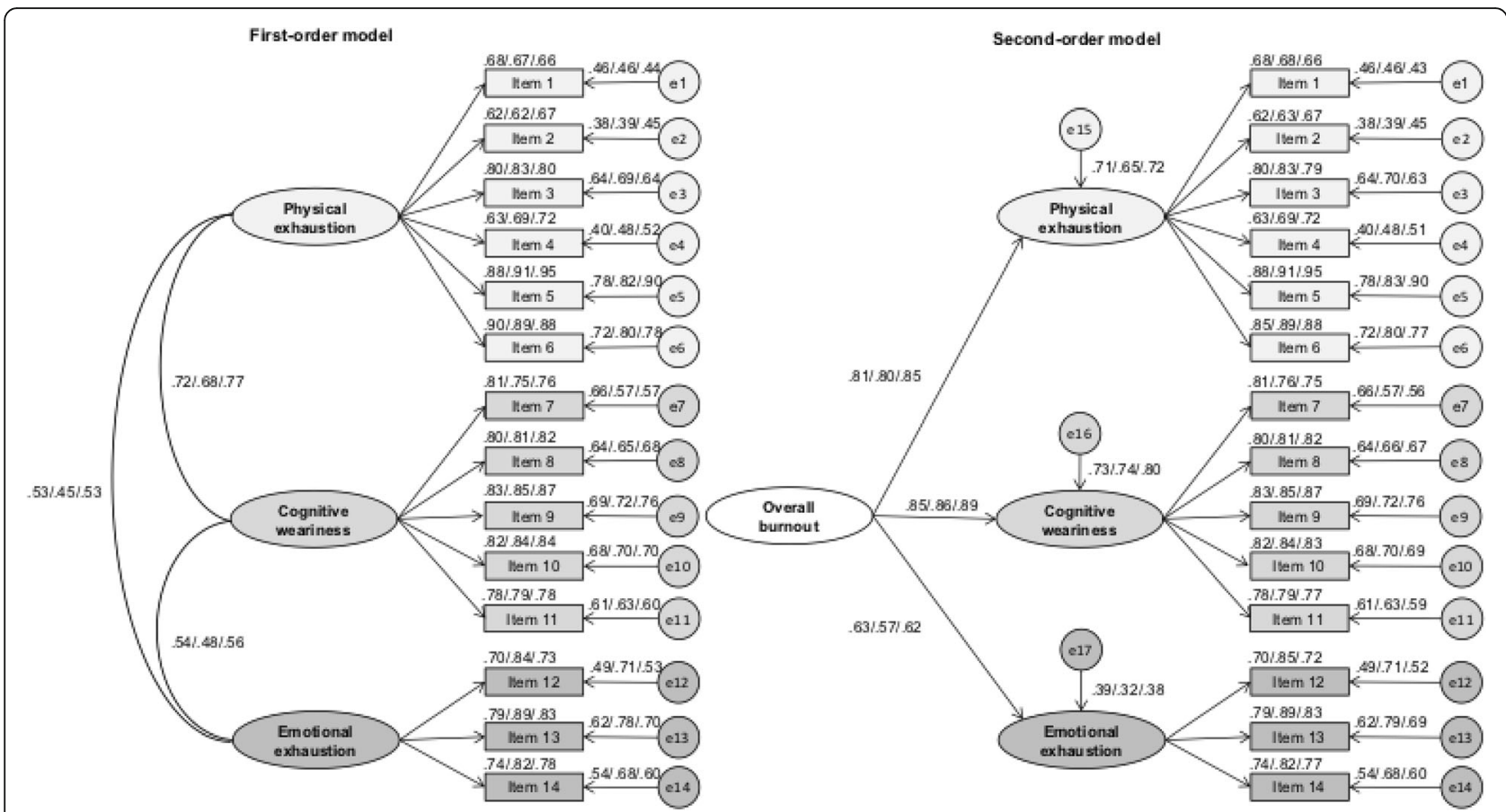

Fig. 2 Factor loadings for confirmatory factor analysis for first- and second-order models, after having tested for measurement invariance across samples. First coefficient: young elite athletes. Second coefficient: high school students. Third coefficient: vocational students

which is consistent with a previous study with Swiss vocational students [50].

Fourth, our findings support the discriminant validity of the SMBM. While our findings corroborate previous studies showing that the SMBM measures are at least moderately correlated with depressive symptoms $[22,24$, 61 , the strength of the correlations varied across our three study populations ( $r=.39$ to .51$)$, with the highest correlations found in high school students. While we acknowledge that there is a certain overlap between these two constructs, the fact that the SMBM overall index only shared between 15 and $26 \%$ of variance indicates that symptoms of burnout and depression are far from being identical constructs among adolescents. As suggested by Melamed et al. [9], some degree of overlap between burnout and depression is expected because both the definition of burnout and depression include fatigue and loss of energy as characterizing criteria. Schonfeld and Bianchi [22], however, recently argued that past research might have underestimated the overlap between burnout and depression. In their study with 1386 teachers, for instance, they reported a correlation of $r=.77(p<.001)$ between the SMBM and the PHQ-9. Moreover, $86 \%$ of the teachers identified as burned out met criteria for provisional diagnoses of depression. Nevertheless, this finding needs to be interpreted with caution because Schonfeld and Bianchi [22] used an arbitrary cut-off to classify participants into groups with versus without burnout $(\geq 5.50)$, which was considerably higher than the empirically validated threshold suggested by Lundgren-Nilsson and colleagues [54]. We are aware that Lundgren-Nilsson et al.'s cut-off is based on the SMBQ (Shirom-Melamed Burnout Questionnaire $=\mathrm{a}$ slightly extended version of the SMBM) and therefore might not be perfectly applicable for the SMBM (despite a strong overlap between the items of the two instruments).

Table 4 Goodness-of-fit indices for testing measurement invariance across samples

\begin{tabular}{|c|c|c|c|c|c|c|c|c|c|c|}
\hline & \multicolumn{5}{|c|}{ First-order model } & \multicolumn{5}{|c|}{ Second-order model } \\
\hline & $\overline{\mathrm{CFI}}$ & TLI & $\mathrm{NFI}$ & RMSEA & $\Delta x^{2}$ & $\overline{\mathrm{CFI}}$ & TLI & $\mathrm{NFI}$ & RMSEA & $\Delta x^{2}$ \\
\hline Default model & .97 & .96 & .93 & $.04(.03, .04)$ & & .97 & .96 & .93 & $.04(.03, .04)$ & \\
\hline + Factor loadings set equally across samples & .96 & .96 & .93 & $.04(.03, .04)$ & $p=.212$ & .96 & .96 & .93 & $.04(.03, .04)$ & $p=.212$ \\
\hline $\begin{array}{l}\text { + Factor loadings and inter-factor correlations } \\
\text { (first-order model) or regression weights } \\
\text { (second-order model) set equally across } \\
\text { samples }\end{array}$ & .96 & .96 & .93 & $.04(.03, .04)$ & $p=.363$ & .96 & .96 & .93 & $.04(.03, .04)$ & $p=.170$ \\
\hline
\end{tabular}


Nevertheless, we still prefer this empirically derived threshold in comparison to any arbitrary cut-off value. In summary, we believe that our findings corroborate the discriminant validity of the SMBM because the percentage of adolescents who were simultaneously classified into the group with high burnout levels and high levels of depressive symptoms was not too high, with $20 \%$ among vocational students, $26 \%$ among young elite athletes, and 53\% among high school students.

Fifth, our assumption that female participants would score higher on burnout symptoms than male participants was partly confirmed. While significant gender differences were found in high school students and young elite athletes, boys and girls did not differ among vocational students. The inconsistent pattern of finding is in line with previous research. Thus, while studies with adolescents mostly supported gender differences [27, 45], among adult workers, male and female participants did not always differ from each other $[59,62]$. In the present study, it is possible that the male and female vocational students did not differ from each other because they generally reported lower burnout symptoms than high school students or young elite athletes. Accordingly, floor effects might have decreased the odds for higher variances and for detecting a higher variability in the measurements. The fact that vocational students had the lowest SMBM scores was a surprise because it has been suggested that the vocational students are exposed to workloads similar to adult workers and are therefore at risk for elevated stress levels [51]. However, the vocational students participating in the present study were in their first year. Thus, it is likely that burnout symptoms will increase in the third or fourth year of vocational education and training. Finally, in line with previous studies [55, 62], physical fatigue turned out to be the most affected burnout dimension across all three samples, followed by cognitive weariness and emotional exhaustion.

Sixth, our data supported the notion that the measurement model is invariant across samples. A multiple group comparison showed that the overall model fit is excellent. Setting factor loadings and inter-factor correlations/regression weights equal across samples did not have a negative impact on the goodness-of-fit indices. Thus, we claim that the SMBM seems to perform equally well in various adolescent samples.

Despite the novelty of our findings, several limitations should be taken into consideration: For instance, due to the cross-sectional nature of our data, it was not possible to test predictive validity and test-retest reliability. Moreover, all three samples consisted of non-clinical populations and we only used measures of self-reported depressive symptoms to examine discriminant validity. Thus, without formal clinical diagnoses, we were not able to validate the cut-off for clinically relevant burnout ( $\geq 4.4$ ), which was previously established by Lundgren-Nilsson et al. [54].

Implications for clinical practice are that $7-12 \%$ of adolescents reported symptoms pointing towards clinically relevant levels of burnout. This percentage is comparable to adult populations $[23,59]$ and shows that more systematic efforts are needed to prevent burnout symptoms. As known from adult studies, burnout symptoms have a relatively high temporal stability, and may track across extended periods of time [77, 78]. In future research, researchers could test strategies to empower students to maintain a better stress-recovery balance [79].

\section{Conclusions}

The SMBM is a frequently used tool in international burnout research. Our study reveals that this instrument has adequate psychometric properties and satisfactory convergent and factorial validity among adolescents. Hence, the SMBM can be used among young people to gather information for screening and treatment planning, which may be of particular interest during the transition from school to working life. There is a clear need to validate the cut-off score for clinically relevant burnout, in order to more accurately judge the clinical significance of the symptoms in early screening.

\section{Endnotes}

${ }^{1}$ Data with regard to the SBI was only available in sample 2 (vocational students). Thus, as suggested by Hypothesis 3, convergent validity between the SMBM and the SBI was only tested in one sample.

${ }^{2}$ In the case of studies with minor participants, the Swiss national legislation (Humanforschungsgesetz HFG) makes a distinction between children ( $\leq 14$ years) and adolescents (15-18 years). In studies with children, parental informed written consent is needed (Art. 22). In studies with adolescents, informed written consent of the adolescent is required. Moreover, parental informed written consent is needed for studies, which bear more than minimal risks. However, all our studies were classified in the lowest risk category. Therefore, no parental informed written consent was required.

\section{Additional file}

Additional file 1: Shirom-Melamed Burnout Measure - German Adolescent Version. (DOCX 17 kb)

\section{Abbreviations}

ASQ: Adolescent Stress Questionnaire; BBI-15: Bergen Burnout Indicator 15; CES-D: Center for Epidemiologic Studies Depression Scale; CFA: Confirmatory Factor Analysis; CFI: Comparative Fit Index; DSM-IV: Diagnostic and Statistical Manual of Mental Disorders (4th Edition); MBI: Maslach Burnout Inventory; ML: Maximum likelihood; NFI: Normed Fit Index; PHQ-9: 9-item Patient 
Health Questionnaire; PSS: Perceived Stress Scale; RMSEA: Root Mean Square Error of Approximation; SBI: School Burnout Inventory; SMBM: ShiromMelamed Burnout Measure; SWLS: Satisfaction with Life Scale; TLI: Tucker Lewis Index

\section{Funding}

Study 1 and 3 were carried out without external funding. Study 2 was financially supported by the Swiss Federal Office of Sport (BASPO; grant number 10-05) and Health Promotion Switzerland (grant number IP18.15).

\section{Availability of data and materials}

Data cannot be shared because in the protocols submitted to the ethical review board, the authors confirmed that only authorized researchers directly involved in this project from University of Basel (Switzerland) will have access to the data.

\section{Authors' contributions}

MG conceived the studies, coordinated data collection and data processes, was responsible for data analysis and drafted the manuscript; FC, MM, RS, SB and $S L$ contributed to the design of the studies and data analysis, participated in the interpretation of the data, and critically reviewed the drafted manuscript; all authors read and approved the final manuscript.

\section{Authors' information}

Markus Gerber is assistant professor of sport science at the Department of Sport, Exercise and Health at the University of Basel, Switzerland. Manuel Mücke and René Schilling are PhD students in the Division of Sport and Psychosocial Health at the at the Department of Sport, Exercise and Health at the University of Basel, Switzerland. Flora Colledge is a post-doctoral researcher in the Sport Science Section at the at the Department of Sport, Exercise and Health at the University of Basel, Switzerland. Serge Brand is a senior researcher in the Sport Science Section at the Department of Sport, Exercise and Health at the University of Basel, Switzerland. He also works as a senior researcher and clinical psychologist at the Center for Affective, Stress and Sleep Disorders, Psychiatric Clinics of the University of Basel, Basel, Switzerland. Finally, he is a visiting professor at Kermanshah University of Medical Sciences (KUMS), Substance Abuse Research Center and Sleep Disorders Research Center; Kermanshah, Iran. Sebastian Ludyga is a postdoctoral researcher in the Sport Science Section at the at the Department of Sport, Exercise and Health at the University of Basel, Switzerland.

\section{Ethics approval and consent to participants}

Ethics approval has been obtained for all three studies before data assessment from the local ethical review board (Ethical Review Board of Northwestern and Central Switzerland, EKNZ). All participants have provided written informed consent.

\section{Consent for publication}

Not applicable.

\section{Competing interests}

The authors declare that they have no competing interests.

\section{Publisher's Note}

Springer Nature remains neutral with regard to jurisdictional claims in published maps and institutional affiliations.

\section{Received: 23 January 2018 Accepted: 7 August 2018}

Published online: 25 August 2018

\section{References}

1. Schaufeli W, Leiter MP, Maslach C. Burnout: 35 years of research and practice. Career Dev Int. 2009;14:204-20

2. Maslach C, Schaufeli WB, Leiter MP. Job burnout. Ann Rev Psychol. 2001:52:397-422.

3. Kristensen TS, Borritz M, Villadsen E, Christensen KB. The Copenhagen burnout inventory: a new tool for the assessment of burnout. Work Stress. 2005;19:192-207

4. Maslach C, Jackson SE, Leiter MP. Maslach burnout inventory manual. Palo Alto: Consulting Psychology Press; 1996.
5. Schaufeli WB, Taris TW. The conceptualization and measurement of burnout: common ground and worlds apart. Work Stress. 2005;19:256-62.

6. Shirom A, Melamed S. A comparison of the construct validity of two burnout measures in two groups of professionals. Int J Stress Manag. 2006:13:176-200.

7. Melamed S, Kushnir T, Shirom A. Burnout and risk factors for cardiovascular disease. Behav Med. 1992;18:53-60.

8. Shirom A, Melamed S, Toker S, Berliner S, Shapira I. Burnout and health review: current knowledge and future research directions. Int Rev Ind Organ Psychol. 2006;20:269-309.

9. Melamed S, Shirom A, Toker S, Berliner S, Shapira I. Burnout and risk of cardiovascular disease: evidence, possible causal paths, and promising research directions. Psychol Bull. 2006;132:327-53.

10. Shirom A, Westman M, Shamai O, Carel RS. Effects of work overload and burnout on cholesterol and triglycerides levels: the moderating effects of emotional reactivity among male and female employees. J Occup Health Psychol. 1997;2:275-88.

11. Gerber M, Börjesson M, Ljung T, Lindwall M, Jonsdottir I. Fitness moderates the relationship between stress and cardiovascular risk factors. Med Sci Sports Exerc. 2016;48:2075-81.

12. Grossi G, Perski A, Evengard B, Blomkvist V, Orth-Gomer K. Physiological correlates of burnout among women. J Psychosom Res. 2003;55:309-16.

13. Melamed S, Shirom A, Toker S, Shapira I. Burnout and risk of type 2 diabetes: a prospective study of apparently healthy employed persons. Psychosom Med. 2006;68:863-9.

14. Melamed S, Shirom A, Froom P: Burnout and risk of type 2 diabetes mellitus (DM) in Israeli workers. Paper presented at the Work, Stress and Health Conference. Toronto, Ontario, Canada; 2003;20-22

15. Toker S, Shirom A, Shapira I, Berliner S, Melamed S. The association between burnout, depression, anxiety, and inflammation biomarkers: C-reactive protein and birinogen in men and women. J Occup Health Psychol. 2005;10:344-62.

16. Lerman Y, Melamed S, Shragin Y, Kushnir T, Rotgoltz Y, Shirom A. Association between burnout at work and leukocyte adhesiveness/ aggregation. Psychosom Med. 1999;61:828-33.

17. Melamed S, Ugarten U, Shirom A, Kahana L, Lerman Y, Froom P. Chronic burnout, somatic arousal and elevated cortisol levels. J Psychosom Res. 1999;46:591-8.

18. Grossi G, Perski A, Akstedt M, Johannson T, Lindström M, Holm K. The morning salivary cortisol response in burnout. J Psychosom Res. 2005;59:103-11.

19. Soares JJ, Jablonska B. Psychological experiences among primary care patients with and without musculoskeletal pain. Eur J Pain. 2004;8:79-89.

20. Sheiner E, Sheiner E, Carel R, Potashnik G, Shoham-Vardi I. Potential association between male infertility and occupational psychological stress. J Occup Environ Med. 2002:44:1-7.

21. Nordin M, Akerstedt T, Nordin S. Psychometric evaluation and normative data for the Karolinska sleep questionnaire. Sleep and Biological Rhythms. 2013;11:216-26.

22. Schonfeld IS, Bianchi R. Burnout and depression: two entities or one? J Clin Psychol. 2016;72:22-37.

23. Gerber $M$, Jonsdottir $H$, Lindwall M, Ahlborg G. Physical activity in employees with differing occupational stress and mental health profiles: a latent profile analysis. Psychol Sport Exerc. 2014;15:649-58.

24. Toker S, Biron M. Job burnout and depression: unraveling their temporal relationship and considering the role of physical activity. J Appl Psychol. 2012:97:699-710.

25. Schaufeli W, Greenglass ER. Introduction on a special issue on burnout and health. Psychol Health. 2001;16:501-10.

26. Schaufeli WB, Martinez I, Marques Pinto A, Salanova M, Bakker AB. Burnout and engagement in university students: a cross-national study. J Cross-Cult Psychol. 2002;33:464-81.

27. Salmela-Aro K, Kiuru N, Leskinen E, Nurmi J-E. School-burnout inventory (SBI). Reliability and validity. Eur J Psychol Assess. 2009:25:48-57.

28. Almeida G, de Souza H, de Almeida PC, Almeida B, Almeida GH. The prevalence of burnout syndrome in medical students. Arch Clin Psychiatry. 2016:43:6-10.

29. Dahlin $M$, Joneborg N, Runeson B. Performance-based self-esteem and burnout in a cross-sectional study of medical students. Med Teach. 2007:29:43-8.

30. Dahlin ME, Runeson B. Burnout and psychiatric morbidity among medical students entering clinical training: a three year prospective questionnaire and interview-based study. BMC Med Educ. 2007;7:6. 
31. Dyrbye LN, Massie FS Jr, Eacker A, Harper W, Power D, Durning SJ, Thomas MR, Moutier C, Satele D, Sloan J, et al. Relationship between burnout and professional conduct and attitudes among US medical students. JAMA. 2010;304:1173-80.

32. Dyrbye LN, Thomas MR, Huschka MM, Lawson KL, Novotny PJ, Sloan JA, Shanafelt TD. A multicenter study of burnout, depression, and quality of life in minority and nonminority US medical students. Mayo Clin Proc. 2006:81:1435-42

33. Dyrbye LN, Thomas MR, Massie FS, Power DV, Eacker A, Harper W, Durning S, Moutier C, Szydlo DW, Novotny PJ, et al. Burnout and suicidal ideation among U.S. medical students. Ann Int Med. 2008;149:334-41.

34. Santen SA, Holt DB, Kemp JD, Hemphill RR. Burnout in medical students: examining the prevalence and associated factors. South Med J. 2010;103:758-63.

35. Salmela-Aro K, Näätänen P. BBI-10. Nuorten kouluuupumusmenetelmä [method of assessing adolescents' school burnout]. Helsinki: Edita; 2005.

36. Näätänen P, Aro A, Matthiesen S, Salmela-Aro K. Bergen burnout Indicator 15. Helsinki: Edita; 2003.

37. Salmela-Aro K, Näätänen P, Nurmi J-E. The role of work-related personal projects during two burnout interventions: a longitudinal study. Work Stress. 2004;18:208-30.

38. Salmela-Aro K, Kiuru N, Nurmi JE. The role of educational track in adolescents' school burnout: a longitudinal study. Br J Edu Psychol. 2008;78:663-89

39. Salmela-Aro K, Kiuru N, Pietikäinen M, Jokela J. Does school matter? The role of school context in adolescents' school-related burnout. Eur Psychologist. 2008;13:1-13.

40. Kiuru N, Aunola K, Nurmi J, Leskinen E, Salmela-Aro K. Peer group influence and selection in adolescents' school burnout. Merrill-Palmer Quaterly. 2008;54:54.

41. Parker $P$, Salmela-Aro K. Developmental processes in school burnout: a comparison of major developmental models. Learn Ind Diff. 2011;21:244-8.

42. Vasalampi K, Salmela-Aro K, Nurmi J. Adolescents' self-concordance school engagement, and burnout predict their educational trajectories. Eur Psychologist. 2009;14:332-41.

43. Salmela-Aro K, Read S, Minkinen J, Kinnunen JM, Rimpelä A. Immigrant status, gender, and school burnout in Finnish lower secondary school students: A longitudinal study. Int J Behav Dev. 2017: https://doi.org/10. 1177/0165025417690264.

44. Salmela-Aro K, Muotka J, Hakkarainen K, Alho K, Lonka K. School burnout and engagement profiles among digital natives in Finland: a personoriented approach. Eur J Dev Psychol. 2016;13:704-18.

45. Salmela-Aro K, Tynkkynen L. Gendered pathways in school burnout among adolescents. J Adolesc. 2012;35:929-39.

46. Salmela-Aro K, Savolainen $H$, Holopainen L. Depressive symptoms and school burnout during adolescence: evidence from two cross-lagged longitudinal studies. J Youth Adolesc. 2009;38:1316-27.

47. Tuominen-Soini H, Salmela-Aro K. Schoolwork engagement and burnout among Finnish high school students and young adults: profiles, progressions, and educational outcomes. Dev Psychol. 2013;50:649-62.

48. Salmela-Aro K, Upadyaya K. School burnout and engagement in the context of demands-resources model. Br J Edu Psychol. 2014;84:137-51.

49. Walburg V. Burnout among high school students: a literature review. Child Youth Serv Rev. 2014;42:28-33.

50. Gerber M, Lang C, Feldmeth AK, Elliot C, Brand S, Hoslboer-Trachsler E, Pühse U. Burnout and mental health in Swiss vocational students: the moderating role of physical activity. J Res Adolesc. 2015;25:63-74.

51. Elliot C, Lang C, Brand S, Holsboer-Trachsler E, Pühse U, Gerber M. The relationship between meeting vigorous physical activity recommendations and burnout symptoms among adolescents: an exploratory study with vocational students. J Sport Exerc Psychol. 2015;37:180-92.

52. Gerber M, Feldmeth AK, Lang C, Brand S, Elliot C, Holsboer-Trachsler E, Pühse $U$. The relationship between mental toughness, stress, and burnout among adolescents: a longitudinal study with Swiss vocational students. Psychol Rep. 2015;117:703-23.

53. Hobfoll SE, Shirom A. Conservation of resources theory: Applications to stress and management in the workplace. In: Golembiewski RT, editor Handbook of organization behavior. New York: Dekker; 2000. p. 57-81.

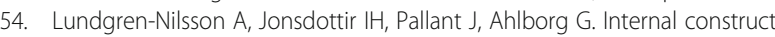
validity of the Shirom-Melamed Burnout Questionnaire (SMBQ). BMC Public Health. 2012: https://doi.org/10.1186/1471-2458-1112-1181.
55. Sassi N, Neveu J-P. Traduction et validation d'une nouvelle mesure d'épuisement professionnel: le Shirom-Melamed Burnout Measure. Can J Behav Sci. 2010;42:177-84.

56. Qiao $\mathrm{H}$, Schaufeli WB. The convergent validity of four burnout measures in a Chinese sample: a confirmatory factor-analytic approach. Appl Psychol. 2011;60:87-111.

57. Comrey AL, Lee HB. A first course in factor analysis. Hillsdale: Erlbaum; 1992.

58. Gerber $M$, Lindwall $M$, Lindegård $A$, Börjesson $M$, Jonsdottir $\| H$. Cardiovascular fitness protects from stress-related symptoms of burnout and depression. Pat Edu Counsel. 2013;93:146-52.

59. Norlund S, Reuterwall C, Höög J, Lindahl B, Janlert U, Slunga Birgander L. Burnout, working conditions and gender - results from the northern Sweden MONICA Study. BMC Public Health. 2010;10: https://doi.org/10. 1186/1471-2458-1110-1326

60. Soares JJ, Grossi G, Sundin O. Burnout among women: associations with demographic/socio-economic, work, life-style and health factors. Arch Womens Ment Health. 2007:10:61-71.

61. Gerber M, Feldmeth AK, Elliot C, Brand S, Holsboer-Trachsler E, Pühse U. Mental health in Swiss vocational students: The moderating role of physical activity. J Res Adolesc. 2014:doi:https://doi.org/10.1111/jora.12097.

62. Böhm D, Stock Gissendanner S, Finkeldey F, John SM, Werfel T, Diepgen TL, Breuer K. Severe occupational hand eczema, job stress and cumulative sickness absence. Occup Med. 2014;64:509-15.

63. Cohen S, Kamarck T, Mermelstein R. A global measure of perceived stress. J Health Soc Behav. 1983;24:385-96.

64. Gerber M, Kalak N, Lemola S, Clough PJ, Perry JL, Pühse U, Elliot C, Holsboer-Trachsler E, Brand S. Are adolescents with high mental toughness levels more resilient against stress? Stress Health. 2013;29:164-71.

65. Leung DYP, Lam TH, Chan SSC. Three versions of perceived stress scale: validation in a sample of Chinese cardiac patients who smoke. BMC Public Health. 2010;10:513-9.

66. Hautzinger M, Bailer M. ADS, Allgemeine Depressionsskala [ADS, General Depression Scale]. Göttingen: Beltz; 1992.

67. Johnson CC, Murray DM, Elder JP, Jobe JB, Dunn AL, Kubik M, Voorhees C, Schachter K. Depressive symptoms and physical activity in adolescent girls. Med Sci Sports Exerc. 2008;40:818-26.

68. Diener E, Emmons RA, Larsen RJ, Griffin S. The satisfaction with life scale. J Person Assess. 1985;49:71-5.

69. Pavot W, Diener E. Review of the satisfaction with life scale. Psychol Assess. 1993;5:164-72.

70. Pavot W, Diener $\mathrm{E}$. The satisfaction with life scale and the emerging construct of life satisfaction. J Pos Psychol. 2008;3:137-52.

71. McDonald RP, Ho RM. Principles and practice in reporting structural equation analyses. Psychol Meth. 2002;7:65-9.

72. Byrne BM. Structural equation modeling with AMOS. Basic concepts, applications, and programming. New York: Taylor \& Francis; 2010

73. Byrne DG, Davenport SC, Mazanov J. Profiles of adolescent stress: the development of the adolescent stress questionnaire (ASQ). J Adolesc 2007;30:393-416.

74. De Vriendt T, Moreno LA, De Henauw S. Chronic stress and obesity in adolescents: scientific evidence and methodological issues for epidemiological research. Nutr Metab Cardiovasc Dis 2009;19:511-19.

75. Kroenke K, Spitzer RL, Williams JBW. The PHQ-9. Validity of a brief depression severity measure. J Gen Int Med. 2001;16:606-13.

76. West SG, Finch JF, Curran PJ. Structural equation models with nonnormal variables: Problems and remedies. In: Hoyle $\mathrm{RH}$, editor. Structural equation modeling Concepts, issues, and applications. Thousand Oakes: Sage; 1995. p. 56-75.

77. Lindwall M, Gerber M, Jonsdottir I, Börjesson M, Ahlborg GJ. The relationships of change in physical activity with change in depression, anxiety, and burnout: a longitudinal study of Swedish healthcare workers. Health Psychol. 2014;33:1309-18.

78. Toppinen-Tanner S, Kalimo R, Mutanen P. The process of burnout in whitecollar and blue-collar jobs: eight-year prospective study of exhaustion. J Organ Behav. 2002;23:555-70.

79. Kellmann M, Kölling S, Pelka M. In: Fuchs R, Gerber M, editors. Erholung und Belastung im Leistungssport. In: Stressregulation und Sport. Heidelberg: Springer; 2017. 